\title{
Clinical, quality of life, and economic value of acromegaly disease control
}

\author{
A. Ben-Shlomo • M. C. Sheppard • J. M. Stephens • \\ S. Pulgar $\cdot$ S. Melmed
}

Published online: 20 May 2011

(C) Springer Science+Business Media, LLC 2011

\begin{abstract}
Although acromegaly is a rare disease, the clinical, economic and health-related quality of life (HRQoL) burden is considerable due to the broad spectrum of comorbidities as well as the need for lifelong management. We performed a comprehensive literature review of the past 12 years (1998-2010) to determine the benefit of disease control (defined as a growth hormone $[\mathrm{GH}]$ concentration $<2.5 \mu \mathrm{g} / \mathrm{l}$ and insulin-like growth factor [IGF]-1 normal for age) on clinical, HRQoL, and economic outcomes. Increased GH and IGF-1 levels and low frequency of somatostatin analogue use directly predicted increased mortality risk. Clinical outcome measures that may improve with disease control include joint articular cartilage thickness, vertebral fractures, left ventricular function, exercise capacity and endurance, lipid profile, and obstructive apnea events. Some evidence suggests an association between controlled disease and improved HRQoL. Total direct treatment costs were higher for patients with uncontrolled compared to controlled disease. Costs incurred for management of comorbidities, and indirect cost could further add to treatment costs. Optimizing disease control in patients with acromegaly appears to improve outcomes. Future studies need to evaluate
\end{abstract}

\footnotetext{
A. Ben-Shlomo $\cdot$ S. Melmed $(\bowtie)$

Pituitary Center, Department of Medicine, Cedars-Sinai Medical Center, 110 George Burns Rd, Los Angeles, CA 90048, USA

e-mail: shlomo.melmed@cshs.org

M. C. Sheppard

University of Birmingham, Birmingham, UK

J. M. Stephens

Pharmerit North America LLC, Bethesda, MD, USA

S. Pulgar

Novartis Pharmaceuticals Corporation, Florham Park, NJ, USA
}

clinical outcomes, as well as HRQoL and comprehensive economic outcomes achieved with controlled disease.

Keywords Acromegaly · Somatostatin analogues . Octreotide · Lanreotide · Quality of life · Morbidity · Mortality

\section{Introduction}

Acromegaly is a chronic, debilitating disorder caused by excessive growth hormone (GH) production predominantly due to a benign pituitary adenoma [1]. The overall annual incidence of acromegaly is approximately 3.3 cases/million, with a prevalence of $58-130$ cases/million people $[2,3]$. Diagnosing acromegaly is hampered by several factors, including the slow, insidious onset of the disease, and variability of biochemical assays beset by inappropriate reference ranges and conversion factors for $\mathrm{GH}$ and insulin-like growth factor (IGF)-1 laboratory tests. Reports in the literature suggest that the mean time from symptom onset to diagnosis is 3-7 years $[4,5]$.

Treatment options for patients with acromegaly include surgery, radiotherapy, and pharmacologic therapies. A cost-effective treatment strategy appears to be first-line surgery followed when needed by second-line octreotide LAR [6]. The goals of treatment are to achieve disease control, while minimizing adverse effects [1]. Disease control for this paper is defined as a GH concentration less than $2.5 \mu \mathrm{g} / \mathrm{l}$ and a normal, age-adjusted IGF-1 level. Many studies report outcomes for patients not achieving disease control using this definition. Therefore, comparison of study results is difficult.

Unfortunately, disease control is elusive for many patients with acromegaly. Data from registry studies show 
Table 1 Percentage of patients achieving disease control in open, uncontrolled registry studies with various treatment strategies

\begin{tabular}{|c|c|c|c|c|c|c|c|c|c|c|}
\hline \multirow[t]{2}{*}{ Treatment } & \multicolumn{4}{|c|}{$\begin{array}{l}\text { Bex et al. (2007) [8] } \\
\text { Belgium and Luxembourg }\end{array}$} & \multicolumn{3}{|c|}{$\begin{array}{l}\text { Petersenn et al. (2008) [7] } \\
\text { Germany }\end{array}$} & \multicolumn{3}{|c|}{$\begin{array}{l}\text { Mestron et al. (2004) [9] } \\
\text { Spain }^{\text {b }}\end{array}$} \\
\hline & $n$ & $\begin{array}{l}\text { Normal } \\
\text { IGF-I } \\
(\%)\end{array}$ & $\begin{array}{l}\mathrm{GH}<2 \mu \mathrm{g} / 1 \\
(\%)\end{array}$ & $\begin{array}{l}\text { Controlled } \\
(\%)\end{array}$ & $n$ & $\begin{array}{l}\text { Normal } \\
\text { IGF-I } \\
(\%)\end{array}$ & $\begin{array}{l}\mathrm{GH}<2.5 \mu \mathrm{g} / \mathrm{l} \\
(\%)\end{array}$ & $n$ & $\begin{array}{l}\text { Controlled } \\
(\%)\end{array}$ & $\begin{array}{l}\text { Active } \\
\text { disease } \\
(\%)\end{array}$ \\
\hline Surgery & 125 & 36 & 36 & 34 & 554 & 54.3 & 67.3 & 246 & 46.3 & 19.5 \\
\hline Radiotherapy & 20 & 50 & 70 & 50 & & NR & NR & 29 & 34.5 & 44.8 \\
\hline Primary medical therapy & 74 & 31 & 51 & 24 & & & & $113^{\mathrm{a}}$ & 7.1 & 92.9 \\
\hline SSA & $57^{\mathrm{c}}$ & NR & NR & 28 & 145 & 36.3 & 30.5 & & & \\
\hline Dopamine agonist & 15 & NR & NR & 13 & & NR & NR & & & \\
\hline Secondary medical therapy & 121 & 53 & 59 & 42 & & & & & & \\
\hline Surgery & 65 & 52 & 56 & 37 & & & & 277 & 35.7 & 64.3 \\
\hline Radiotherapy & 4 & 25 & 25 & 0 & & NR & NR & 42 & 11.9 & 88.1 \\
\hline Surgery + radiotherapy & 52 & 59 & 65 & 52 & & NR & NR & 359 & 27.3 & 72.4 \\
\hline SSA followed by surgery & & & & & 93 & 62.9 & 68.4 & & & \\
\hline Surgery followed by SSA & & & & & 34 & 24.1 & 45.5 & & & \\
\hline
\end{tabular}

GH growth hormone, IGF-1 insulin-like growth factor-1, NR not reported, SSA somatostatin analogue

${ }^{\text {a }} 68.3 \%$ of patients treated with SSA; $31.4 \%$ treated with dopamine agonists; ${ }^{\mathrm{b}}$ Percentages may not add up to $100 \%$ due to missing data;

${ }^{\mathrm{c}}$ Two patients received dopamine agonists in conjunction with SSA

that patients with acromegaly are not effectively treated (Table 1). Specifically, less than $50 \%$ of patients in these registry studies achieved disease control [7-9]. Two of these studies exclusively assessed patients treated with medical therapy. In these two studies, only 7 and $24 \%$ of patients achieved disease control with primary medical therapy and up to $42 \%$ with secondary medical therapy $[8,9]$.

In these registry studies, patients treated with radiotherapy either alone or with surgery or medical therapy were most likely to achieve disease control $[8,9]$. However, the disadvantages of radiotherapy must be considered when evaluating these results. These include a lag time to response ( $>6$ years in most patients), the development of hypopituitarism in over $50 \%$ of patients, and the risk of cerebrovascular events/stroke ( $21 \%$ at 20 years) and secondary brain tumors ( $2 \%$ at 20 years) [10-13].

In general, study results suggest an improvement in several outcomes in patients who lower their GH and/or IGF-1 concentrations with treatment compared to baseline. Less clear is the impact of disease control on health-related quality of life (HRQoL) and economic outcomes. A clear understanding of the potential benefits of disease control, and how this may translate into policy, reimbursement, and clinical decision-making, could improve outcomes for patients with acromegaly. Therefore, we conducted a study to determine the clinical, HRQoL, and economic benefits of achieving disease control in patients with acromegaly. To our knowledge, this is the first attempt to systematically review the impact of disease control defined as both a $\mathrm{GH}<2.5 \mu \mathrm{g} / \mathrm{l}$ and normal age-adjusted IGF-1 levels on these outcomes. We sought to answer the following questions: Do patients with controlled disease live longer than patients with uncontrolled disease? Are comorbidities decreased in patients with controlled compared to uncontrolled disease? Is HRQoL improved in patients with controlled compared to uncontrolled disease? Finally, is there an economic benefit associated with disease control?

\section{Methods}

A comprehensive literature review of the past 12 years (1998-2010) was conducted in MEDLINE, EMBASE, Econlit, and PsychInfo using the search terms acromegaly AND epidemiology, morbidity, mortality, complications, long-term outcomes, costs, economics, QoL, and utilities. Additional searches were conducted to identify clinical trials that evaluated somatostatin analogue, dopamine agonist, or pegvisomant administration on disease control and outcomes. Additional abstracts were identified through article bibliographies and searches in conference proceedings (2003-2009). Prospective or retrospective and cross-sectional studies or meta-analyses that reported on the relationship of comorbidity, long-term outcomes, economic factors, or HRQoL and disease control in adults with acromegaly were retained. Figure 1 summarizes the literature review selection process. 


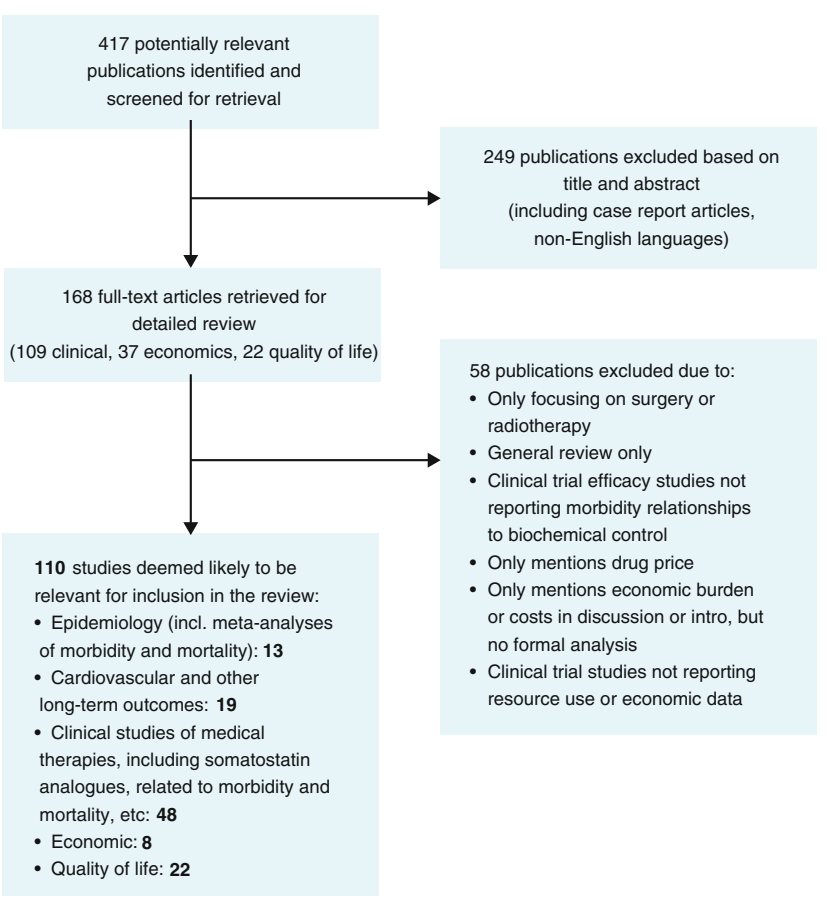

Fig. 1 Flow diagram for study selection

\section{Results}

Do patients with controlled disease live longer?

Overall, mortality is increased in patients with acromegaly [14-22] (Fig. 2; [23, 24]). Results from two meta-analyses suggest that disease control is inversely related to mortality; as disease control improves mortality decreases [23, 24]. Factors found to decrease mortality included disease remission, decreased GH concentrations, normalized IGF-1 concentrations, and increased somatostatin analogue use (Table 2) [23]. These studies also suggest that achieving disease control has the potential to essentially normalize mortality in the acromegaly patient to that of the general population [24].

One exception may be when radiotherapy is included as part of treatment. The meta-analysis by Dekkers et al. found higher mortality in studies before 1995 when patients were more likely to receive radiotherapy as primary treatment [24]. Similarly, Sherlock et al. found a 2-fold increase in mortality in acromegaly patients treated with radiotherapy compared with the general population (SMR 2.1; 95\% CI, 1.7-2.6; $P=0.006$ ) [25]. Specifically, in patients who received radiotherapy, there was a significantly higher increase in the risk of cerebrovascular deaths (SMR 4.1; 95\% CI, 2.3-6.6; $P=0.034$ ) [25].

Are comorbidities decreased with controlled disease?

Many patients with acromegaly have untreated disease for several years prior to diagnosis and a spectrum of morbidities are apparent. In one study, $40 \%$ of patients at diagnosis had multiple comorbidities [4]. Some, but not all, of these comorbidities can be reversed upon cure or control of the patient's condition [2]. Results from several studies show significant improvements in a number of key acromegaly comorbidities when disease control is achieved (Table 3).

\section{Glucose metabolism}

Altered glucose metabolism in patients with acromegaly varies from impaired glucose tolerance (16-46\% of patients) to overt diabetes mellitus (19-56\% of patients) [26]. Glucose-related metabolic abnormalities can be reversed in patients with acromegaly when GH and IGF-1 concentrations are controlled by either surgery or administration of pharmacologic therapy [33]. Surgery improves glucose tolerance and pegvisomant appears to improve insulin sensitivity and carbohydrate metabolism [26].
Fig. 2 Acromegaly and mortality: observed deaths in acromegaly versus expected deaths in general population $[23,24]$

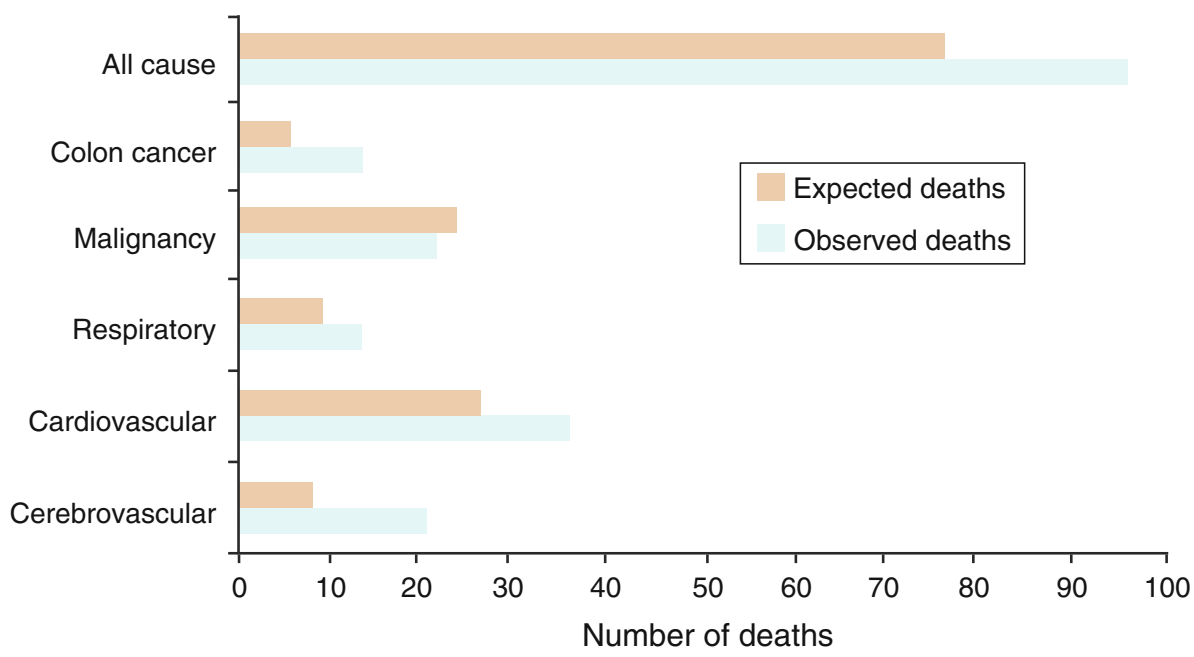


Table 2 Influence of disease control and somatostatin analogue use on mortality in patients with acromegaly [23]

\begin{tabular}{lll}
\hline Acromegaly population & $\begin{array}{l}\text { SMR } \\
(95 \% \mathrm{CI})\end{array}$ & $\begin{array}{l}\text { Risk ratio } \\
(P \text { value })\end{array}$ \\
\hline Remission in $>70 \%$ of patients & $1.2(1.0-1.5)$ & $1.7(<0.05)$ \\
Remission in $<70 \%$ of patients & $2.0(1.6-2.3)$ & \\
$\mathrm{GH}<2.5 \mu \mathrm{g} / 1$ & $1.1(0.9-1.4)$ & $1.7(<0.05)$ \\
$\mathrm{GH}>2.5 \mu \mathrm{g} / \mathrm{l}$ & $1.9(1.5-2.4)$ & \\
Normal IGF-I & $1.1(0.9-1.4)$ & $2.3(<0.05)$ \\
Increased IGF-I & $2.5(1.6-4.0)$ & \\
Somatostatin analogue use & $1.2(1.0-1.5)$ & $1.7(<0.001)$ \\
$\quad$ in $>30 \%$ patients & & \\
Somatostatin analogue use & $2.0(1.6-2.3)$ & \\
$\quad$ in $<30 \%$ of patients & &
\end{tabular}

$C I$ confidence interval, $G H$ growth hormone, $I G F-1$ insulin-like growth factor-1, SMR standardized mortality ratio

Administration of a somatostatin analogue can improve insulin resistance induced by elevated GH levels [26], and may reduce insulin needs in overt diabetes. However, somatostatin therapy may also decrease islet cell insulin secretion thereby worsening glucose-related metabolic abnormalities [34]. Nevertheless, in most patients, these effects counterbalance each other and patients maintain an euglycemic state.

\section{Cardiovascular effects/hypertension}

The hallmark cardiac effect in patients with acromegaly is concentric biventricular hypertrophy due to thickened cardiac walls [26]. Cardiac hypertrophy can occur in patients with acromegaly in the absence of hypertension but is further aggravated by hypertension and glucose abnormalities [26]. In fact, the most important factor in the development of acromegalic cardiac hypertrophy is arterial hypertension [35]. Other cardiovascular effects that occur in patients with acromegaly include arrhythmias such as ectopic beats, paroxysmal atrial fibrillation, paroxysmal supraventricular tachycardia, sick sinus syndrome, ventricular tachycardia, and bundle branch block, and cardiac valve disease [36].

Treatment of acromegaly can slow cardiac disease progression and ultimately decrease cardiovascular morbidity and mortality [26]. Data from numerous studies show decreased left ventricular hypertrophy [30, 37-41], improvement in diastolic function [30, 37, 39-43], no change or improved systolic function [30, 37, 39-43], decreased heart rate [30, 38, 43], and decreased arrhythmias [41] following treatment with a somatostatin analogue. Table 4 highlights cardiac function endpoints from one study as an example of what might be achieved with disease control in patients with acromegaly [29].
Furthermore, in terms of impact on hypertension, acromegaly patients with controlled disease (defined as a normal IGF-1 concentration) have shown lower systolic $(P=0.04)$ and diastolic $(P=0.002)$ blood pressure values compared to those with uncontrolled disease [44].

\section{Skeletal system complications}

The most frequent complaint by patients with acromegaly is arthropathy [26]; up to $70 \%$ of patients with acromegaly have acral complications at diagnosis. It is currently unknown whether GH and IGF-1 control can reverse arthropathy in patients with acromegaly, however, improvement in signs and symptoms was demonstrated $[45,46]$. Improvements observed with disease control include decreased carpal tunnel syndrome and a reduction in joint space thickness, as measured by articular cartilage thickness via ultrasound [26, 31, 47, 48] (Fig. 3) [31].

Vertebral fractures also appear to be decreased in patients with controlled compared to uncontrolled disease [32]. In this study, patients with controlled disease had a $33 \%$ fracture rate compared with an $80 \%$ fracture rate in patients with uncontrolled disease. In fact, patients with uncontrolled acromegaly experienced fractures even with normal bone mineral density, suggesting that normal bone mineral density is not protective against vertebral fractures in patients with uncontrolled disease. Patients with controlled disease had a 2.4-fold lower fracture rate compared with uncontrolled disease $(P<0.008)$.

\section{Sleep apnea}

Sleep apnea syndrome is defined as the presence of 5-10 sleep apnea episodes or hypopneas of at least 10 seconds duration/hour of nocturnal sleep [49]. Patients with acromegaly can have central, obstructive, or mixed sleep apnea, with obstructive sleep apnea being the most common form.

Results of some studies suggest an improvement in sleep apnea in patients achieving disease control [26, 28, 33]. In a small cross-sectional study, Davi et al. found that a higher proportion of patients with uncontrolled compared to controlled disease had obstructive sleep apnea (55 and $39 \%$, respectively) [28]. Additionally, the average number of obstructive apnea events/hour was roughly 4 times higher among those with uncontrolled disease. Somatostatin analogue administration may be beneficial in some patients, particularly those with mixed or central sleep apnea [26].

\section{Lipid metabolism}

Achievement of disease control and treatment with somatostatin analogue therapy appears to have beneficial 
Table 3 Impact of disease control ( $\mathrm{GH}<2.5 \mu \mathrm{g} / \mathrm{l}$ and IGF-1 normal for age) on morbidity in patients with acromegaly

\begin{tabular}{lll}
\hline Complication & $\begin{array}{l}\text { Prevalence in } \\
\text { acromegaly }\end{array}$ & Improvement with disease control \\
& {$[8,9,26](\%)$} & \\
\hline
\end{tabular}

Lipid abnormalities $26 \quad$ Vilar et al. (2007) [27] Metabolic profile study $N=98 ; 12$ controlled, 50 uncontrolled, 36 healthy controls

Sleep apnea

Cardiovascular disease

$14-18$

Arthropathy

20-70

Spinal involvement

$40-50$
Davi et al. (2008) [28] Sleep apnea syndrome in acromegaly patients $N=36,18$ controlled disease; 18 uncontrolled/active disease

Colao et al. (2000) [30] LV structure and performance study in somatostatin analogue-naïve patients with testing 3- and 6-months after octreotide LAR $N=15,9$ controlled, 6 uncontrolled

Colao et al. (2003) [31] Joint thickness study of de novo acromegaly patients following 12 months of octreotide LAR $N=90 ; 30$ de novo patients, 30 cured

Bonadonna et al. (2005) [32] Vertebral fractures in postmenopausal women with acromegaly $N=72 ; 21$ controlled, 15 uncontrolled, 36 postmenopausal controls patients; 30 healthy controls
Controlled versus uncontrolled

$11 \%$ decrease in LDL $(P=0.01)$

$31 \%$ decrease in triglycerides $(P<0.001)$

$61 \%$ decrease in VLDL $(P<0.001)$

$70 \%$ decrease in $\operatorname{Lp}(\mathrm{a})(P=0.023)$

$53 \%$ decrease in HOMA-IR $(P=0.032)$

Prevalence of sleep apnea

Controlled $39 \%$

Uncontrolled 56\%

Controlled versus uncontrolled

$\sim 4$-fold decrease in obstructive apnea events/hour

$\sim 2$-fold decrease in apnea/hypopnea index

Controlled versus uncontrolled $(P<0.05$ for all comparisons)

$30 \%$ decrease in inter-ventricular septum diameter

$36 \%$ decrease in left ventricular mass

$35 \%$ decrease in left ventricular mass index

$23 \%$ increase in fractional shortening

$21 \%$ increase in ejection fraction

Controlled $^{\mathrm{a}}$

$21 \%$ decrease in left ventricular mass index $(P \leq 0.001)$

$13 \%$ increase in ejection fraction at rest $(P=0.005)$

$17 \%$ increase in ejection fraction at peak exercise $(P=0.002)$

$30 \%$ increase in exercise duration $(P=0.01)$

$16 \%$ increase in exercise capacity $(P=0.05)$

Well-controlled patients normalized joint thickness

$61 \%$ at shoulder, $89 \%$ at right knee

Maximum decrease in joint thickness after 12 months of long-acting octreotide treatment

Uncontrolled 5-8\% across all joint sites

Controlled 25-29\% across all joint sites

Controlled $33 \%$ fracture rate (only in patients with low bone mineral density)

Uncontrolled $80 \%$ fracture rate (even with normal bone mineral density)

Postmenopausal controls $31 \%$ fracture rate 2.4-fold decrease in significant events $(P<0.008)$

GH growth hormone, HOMA-IR homeostasis model assessment of insulin resistance, IGF-1 insulin-like growth factor-1, $L D L$ low-density lipoprotein, $L p(a)$ lipoprotein (a), $L V$ left ventricular, $V L D L$ very low-density lipoprotein

${ }^{a}$ Patients controlled following 6 months of long-acting octreotide treatment, comparison made between baseline and 6 months laboratory values

effects on lipid metabolism, with studies reporting significant decreases in total cholesterol, low-density lipoprotein (LDL) cholesterol, and triglyceride levels and increases in high-density lipoprotein (HDL) associated with octreotide therapy [38, 50, 51]. Similar results are reported following treatment with lanreotide [52]. In a study designed to determine the affect of disease control on lipid metabolism, patients with controlled versus uncontrolled acromegaly had significantly lower triglycerides $(153.1 \pm 64.5$ vs. $223.4 \pm 107.4 \mathrm{mg} / \mathrm{dl} ; \quad P<0.001$ ), very low-density 
Table 4 Improvement in cardiac function with disease control [29]

\begin{tabular}{lcccc}
\hline Variable & Untreated & Uncontrolled & Well controlled & Cured \\
\hline IVSD $(\mathrm{mm})$ & $13.1 \pm 1.6$ & $13.8 \pm 1.1$ & $9.6 \pm 0.5^{\mathrm{a}, \mathrm{b}}$ & $10.6 \pm 1.3$ \\
LVM $(\mathrm{g})$ & $250 \pm 48$ & $314 \pm 57$ & $201 \pm 20^{\mathrm{b}}$ & $199 \pm 43$ \\
LVMI $\left(\mathrm{g} / \mathrm{m}^{2}\right)$ & $126.0 \pm 22.5$ & $153 \pm 27.7$ & $99.6 \pm 9.5^{\mathrm{b}}$ & $100.3 \pm 19.5$ \\
FS $(\%)$ & $30.9 \pm 2.5$ & $29.9 \pm 2.6$ & $36.8 \pm 1.7^{\mathrm{b}}$ & $37.4 \pm 1.4^{\mathrm{c}}$ \\
LVEF $(\%)$ & $57.8 \pm 3.8$ & $59.7 \pm 2.81$ & $72.4 \pm 2.6^{\mathrm{a}, \mathrm{b}}$ & $73 \pm 1.8^{\mathrm{c}, \mathrm{d}}$ \\
\hline
\end{tabular}

$F S$ fractional shortening, IVSD inter-ventricular septum diameter, $L V E F$ left ventricular ejection fraction, $L V M$ left ventricular mass, $L V M I$ LVM index, LVM/body surface area

Adapted from van Thiel et al. [29]. (C) Society of the European Journal of Endocrinology (2005). Reproduced by permission

${ }^{\mathrm{a}} P<0.05$ untreated versus well controlled; ${ }^{\mathrm{b}} P<0.05$ uncontrolled versus well controlled; ${ }^{\mathrm{c}} P<0.05$ uncontrolled versus cured; ${ }^{\mathrm{d}} P<0.5$ untreated versus cured

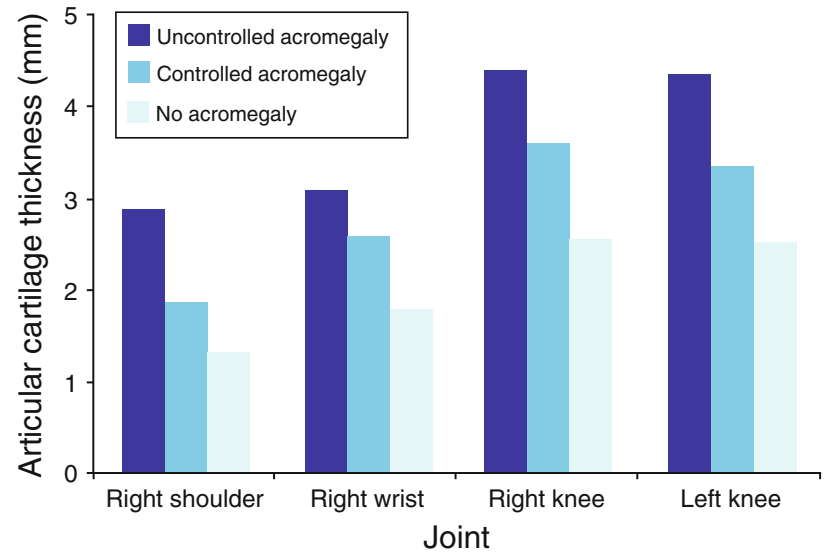

Fig. 3 Comparison of joint articular cartilage thickness in patients with controlled acromegaly, uncontrolled acromegaly, and no acromegaly. Adapted from Colao et al. [31]. (C) European Society of Endocrinology. Reproduced by permission

lipoprotein (VLDL) cholesterol (44.2 \pm 14.3 vs. $112.8 \pm$ $22.2 \mathrm{mg} / \mathrm{dl} ; P<0.001)$, and lipoprotein (a) $(25.5 \pm 15.8$ vs. $85.1 \pm 56.1 \mathrm{mg} / \mathrm{dl} ; P=0.023)$ and significantly higher HDL cholesterol $(45.3 \pm 14.0$ vs. $44.6 \pm 9.9 \mathrm{mg} / \mathrm{dl}$; $P<0.001)$ concentrations [27].

\section{Is HRQoL improved with controlled disease?}

Four published studies compared HRQoL in patients with controlled and uncontrolled acromegaly using the AcroQoL instrument [53-56]. The AcroQoL is a disease-specific questionnaire designed to evaluate HRQoL in patients with acromegaly (Table 5) [57]. A significant difference between AcroQoL scores in controlled and uncontrolled patients was found only in the study by Trepp et al. [54]. This was the smallest of the four studies, enrolling only 33 patients with acromegaly; 21 patients $(64 \%)$ were classified as being in remission (random $\mathrm{GH}$ value or a nadir $\mathrm{GH}$ value following an oral glucose tolerance test [OGTT]
Table 5 The AcroQoL questionnaire [57]

Scale 1: Physical

My legs are weak

I get depressed

I have problems carrying out my usual activities

The illness affects my performance at work or in my usual tasks

My joints ache

I am usually tired

I feel like a sick person

I feel weak

Scale 2-1: Psychological/appearance

I feel ugly

I look awful in photographs

I look different in the mirror

Some parts of my body (nose, feet, hands...) are too big

I have problems doing things with my hands, for example, sewing or handling tools

I snore at night

It is hard for me to articulate words due to the size of my tongue

Scale 2-2: Psychological/personal relations

I avoid going out very much with friends because of my appearance

I try to avoid socializing

I feel rejected by people because of my illness

People stare at me because of my appearance

I have problems with sexual relationships

The physical changes produced by my illness govern my life

I have little sexual appetite

Scales measured in frequency of occurrence (always, most of the time, sometimes, rarely, never) or degree of agreement (completely agree, moderately agree, neither agree nor disagree, moderately disagree, completely disagree)

$<1 \mu \mathrm{g} / \mathrm{l}$ and normal IGF-1 levels), six patients (18\%) as having active disease, and the remaining six patients (18\%) as having discordant results. Patients with active disease 
had significantly lower total AcroQoL scores $(P=0.01)$ and lower scores on the physical $(P=0.021)$ and psychological scales $(P=0.023)$, and the personal relations subscale $(P=0.042)$ suggesting improved HRQoL with disease control.

Is there an economic benefit with disease control?

Two studies compared the economic burden of controlled and uncontrolled acromegaly $[58,59]$. Both studies evaluated direct costs from the European perspective. No highquality studies were identified in the United States that specifically assessed patient costs with controlled versus uncontrolled disease.

Didoni et al. performed a cost-of-illness study assessing health resource consumption due to acromegaly and associated comorbidities [58]. This retrospective study evaluated approximately 7 years of data obtained from 142 patients treated at two hospitals in northern Italy in the Italian Healthcare Service. Direct costs analyzed included those for hospitalizations, diagnostic and laboratory tests, specialist visits, and drugs. Ninety-one patients had controlled disease ( $\mathrm{GH}$ following an OGTT $<1 \mu \mathrm{g} / \mathrm{l}$ and IGF-1 normal for age) and 43 patients had uncontrolled disease (GH following an OGTT $>1 \mu \mathrm{g} / \mathrm{l}$ and/or an increased IGF-1 for age). Total annual costs were approximately 1.6 times higher in patients with uncontrolled $(€ 12,533)$ compared to controlled disease $(€ 7,968)$. Drug costs accounted for most of the cost differences between the controlled and uncontrolled patients. Drug costs were 1.74 times higher in patients with uncontrolled versus controlled disease. Although the rate of overall comorbidities was similar between the controlled and uncontrolled groups, the rate of diabetes was $17 \%$ higher and hypertension $44 \%$ higher in the uncontrolled than controlled group. The economic value of reducing rates of diabetes and hypertension could be substantial, as this study suggests $60 \%$ higher costs related to these two comorbidities in patients with uncontrolled acromegaly.

Luque-Ramírez et al. determined costs for 11 acromegaly patients with invasive pituitary adenomas [59]. Data were analyzed for 4 years following diagnosis. Costs were determined using data from the Centre for Health Economics and Social Policy Studies and the Official College of Pharmacists in Spain (year not specified). All patients underwent transsphenoidal pituitary surgery; 10 patients also required medical therapy (somatostatin analogue $n=6$; bromocriptine $n=3$; somatostatin analogue plus bromocriptine $n=1$ ); six patients also required fractionated radiotherapy. A total of five patients had controlled disease (GH $<2 \mu \mathrm{g} / 1$ and an IGF-1 level normal for age) and six patients had uncontrolled disease (five patients had a GH $>2 \mu \mathrm{g} / \mathrm{l}$ but normal IGF-I and one patient had a $\mathrm{GH}<2 \mu \mathrm{g} / \mathrm{l}$ but an elevated IGF-I level). The mean annual global cost/patient was $€ 7,570$. Interestingly, in this study annual global treatment costs were higher in patients with controlled disease $(€ 9,874)$ versus uncontrolled disease $(€ 7,072)$. However, three patients with uncontrolled disease received only bromocriptine, a lower cost therapy than somatostatin analogues. Analysis of somatostatin analogue therapy costs found higher treatment costs in patients with uncontrolled compared to controlled disease. Not surprisingly, annual treatment costs were lowest for the patient cured with surgery alone $(€ 1,343)$.

\section{Discussion}

Disease burden is defined as the impact of a health problem measured by financial cost, mortality, morbidity, or other indicators [60]. The objective of this assessment was to determine acromegaly disease burden as measured by clinical, HRQoL, and economic outcomes. Results from this critical literature review show that the clinical burden of controlled and uncontrolled acromegaly is fairly well defined in terms of mortality. In comparison, the burden of controlled and uncontrolled acromegaly in terms of morbidity, HRQoL, and direct and indirect costs is less defined. Few studies assessed the impact of disease control on direct medical care costs and HRQoL. No studies assessed the impact of disease control on indirect costs such as work productivity/employment.

A review of data from registry studies shows that the majority of patients with acromegaly do not achieve disease control [7-9]. Results from this review document the benefits of controlled compared with uncontrolled disease. Mortality, morbidity, and costs are all decreased in patients with controlled compared to uncontrolled disease. The effect of controlled disease on HRQoL is less clear. Results from one study suggest improved HRQoL in patients with controlled compared to uncontrolled disease [54]. Several possibilities may explain why an association between HRQoL and disease control is not evident. First, the AcroQoL tool may not be sufficiently sensitive to detect differences in HRQoL between controlled and uncontrolled patients. Second, patients with acromegaly continue to have cosmetic and orthopedic deformities because of the lag time encountered to diagnosis, and in many cases these are not reversed with treatment. The effect of these deformities on HRQoL is not known. Finally, the influence of comorbidities on HRQoL measures is not known. Unfortunately, the rarity of this disorder makes evaluating the influence of comorbidities difficult. 
Conceptualizing an outcomes tool for acromegaly

When presented with an acromegaly diagnosis, patients typically have numerous questions concerning how this disease will impact the rest of their life. Healthcare providers are in need of a tool to aid them in addressing these questions. This tool needs to incorporate data on clinical outcomes such as morbidity and mortality, HRQoL outcomes, and economic outcomes including direct and indirect costs. This tool would benefit patients, healthcare providers and policy makers evaluating treatment options for this patient population. Major gaps in the existing literature surrounding health outcomes analyses in acromegaly include lack of integration of the impact that comorbidities have on mortality, costs, HRQoL, and individual patient productivity both before and after diagnosis in situations of suboptimal disease control.

Figure 4 outlines a conceptual model for assessing relevant health economic outcomes in acromegaly. For example, the economic impact of reducing comorbidities with strict biochemical control could be considered (e.g., cardiac/hypertension, diabetes). One approach, in the absence of acromegaly-specific data, would be to assess the average treatment cost for each comorbidity from published medical literature. For example, the cost of a vertebral fracture is estimated at more than $\$ 3,800$ in the first year [61], the annual/patient cost of cardiovascular disease is more than $\$ 6,300 /$ year [62], the cost of sleep apnea is more than $\$ 2,200$ [63], and the cost of arthropathy is more than $\$ 3,100$ annually [64]. These patients are at risk of multiple comorbidities with suboptimal control, thus, the additive economic impact of reduced comorbidities may be significant. In addition, shortening the latency period between onset of disease, diagnosis, and treatment will likely reduce the burden of high-cost complications that may not be fully reversible such as diabetes, hypertension, and facial deformity. There is a clear need to develop a full assessment of the economic burden of acromegaly, as well as the comparative effectiveness of available treatment options using both economic modeling and retrospective

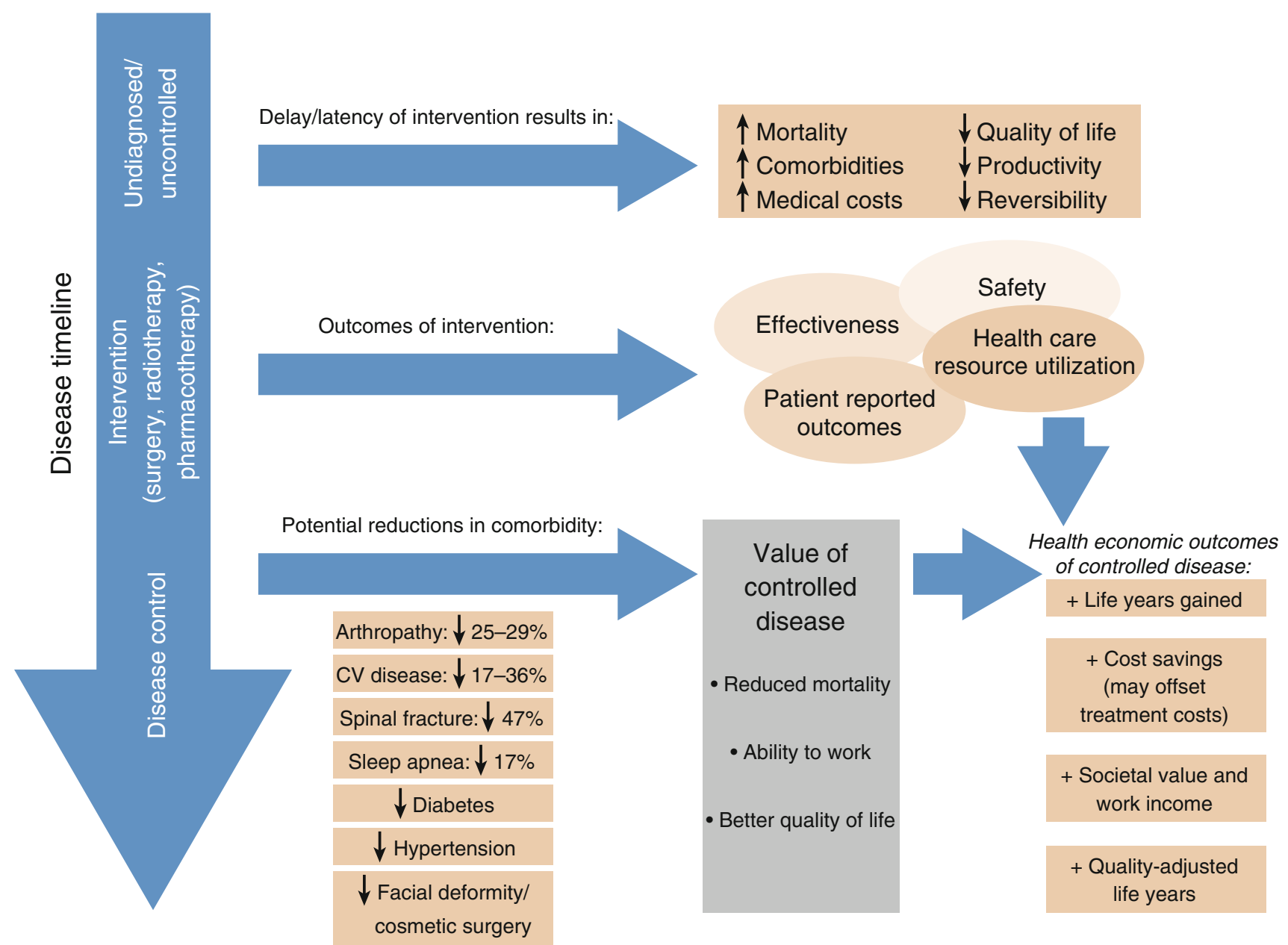

Fig. 4 Conceptual model of the value of disease control in acromegaly 
data analysis. This could be achieved by analyzing claims data or undertaking extensive chart reviews.

\section{Conclusions}

Although the benefits of acromegaly disease control are well-known, there are many unanswered questions about the benefits of controlled compared with uncontrolled disease regarding the dimensions of morbidities, HRQoL, and costs. Benefits of controlled disease, defined as a $\mathrm{GH}<2.5 \mu \mathrm{g} / \mathrm{l}$ and a normal age-adjusted IGF-1 level, must clearly be defined. The availability of a tool to aid healthcare providers, policy makers, and patients in determining the effects of disease control on clinical, HRQoL, and economic outcomes is needed. Future studies need to evaluate clinical outcomes and also HRQoL and economic outcomes achieved with controlled disease. Incorporation of these data into a tool, which healthcare providers and policy makers could use to evaluate treatment options and determine the most effective treatment plans would be invaluable for patients.

Acknowledgments Authors are grateful to Beth Lesher, PharmD for expert assistance.

Conflict of interest This research was funded by Novartis Pharmaceuticals.

\section{References}

1. Melmed S (2006) Medical progress: acromegaly. N Engl J Med 355:2558-2573

2. Holdaway IM, Rajasoorya C (1999) Epidemiology of acromegaly. Pituitary 2:29-41

3. Reddy R, Hope S, Wass J (2010) Acromegaly. BMJ 341:c4189

4. Nachtigall L, Delgado A, Swearingen B, Lee H, Zerikly R, Klibanski A (2008) Changing patterns in diagnosis and therapy of acromegaly over two decades. J Clin Endocrinol Metab 93: 2035-2041

5. Drange MR, Fram NR, Herman-Bonert V, Melmed S (2000) Pituitary tumor registry: a novel clinical resource. J Clin Endocrinol Metab 85:168-174

6. Biermasz NR, Roelfsema F, Pereira AM, Romijn JA (2009) Costeffectiveness of lanreotide autogel in treatment algorithms of acromegaly. Expert Rev Pharmacoecon Outcomes Res 9:223-234

7. Petersenn S, Buchfelder M, Reincke M, Strasburger CM, Franz H, Lohmann R, Quabbe HJ, Plockinger U (2008) Results of surgical and somatostatin analog therapies and their combination in acromegaly: a retrospective analysis of the German acromegaly register. Eur J Endocrinol 159:525-532

8. Bex M, Abs R, T'Sjoen G, Mockel J, Velkeniers B, Muermans K, Maiter D (2007) AcroBel: the Belgian registry on acromegaly: a survey of the 'real-life' outcome in 418 acromegalic subjects. Eur J Endocrinol 157:399-409

9. Mestron A, Webb SM, Astorga R, Benito P, Catala M, Gaztambide S, Gomez JM, Halperin I, Lucas-Morante T, Moreno B, Obiols G, De PP, Paramo C, Pico A, Torres E, Varela C, Vazquez
JA, Zamora J, Albareda M, Gilabert M (2004) Epidemiology, clinical characteristics, outcome, morbidity and mortality in acromegaly based on the Spanish acromegaly registry (Registro Espanol de Acromegalia, REA). Eur J Endocrinol 151:439-446

10. Melmed S, Colao A, Barkan A, Molitch M, Grossman AB, Kleinberg D, Clemmons D, Chanson P, Laws E, Schlechte J, Vance ML, Ho K, Giustina A (2009) Guidelines for acromegaly management: an update. J Clin Endocrinol Metab 94:1509-1517

11. Feelders RA, Hofland LJ, van Aken MO, Neggers SJ, Lamberts SW, de Herder WW, van der Lely A-J (2009) Medical therapy of acromegaly: efficacy and safety of somatostatin analogues. Drugs 69:2207-2226

12. Brada M, Ashley S, Ford D, Traish D, Burchell L, Rajan B (2002) Cerebrovascular mortality in patients with pituitary adenoma. Clin Endocrinol 57:713-717

13. Minniti G, Gilbert DC, Brada M (2009) Modern techniques for pituitary radiotherapy. Rev Endocr Metab Disord 10:135-144

14. Beauregard C, Truong U, Hardy J, Serri O (2003) Long-term outcome and mortality after transsphenoidal adenomectomy for acromegaly. Clin Endocrinol 58:86-91

15. Ayuk J, Clayton RN, Holder G, Sheppard MC, Stewart PM, Bates AS (2004) Growth hormone and pituitary radiotherapy, but not serum insulin-like growth factor-I concentrations, predict excess mortality in patients with acromegaly. J Clin Endocrinol Metab 89:1613-1617

16. Trepp R, Stettler C, Zwahlen M, Seiler R, Diem P, Christ ER (2005) Treatment outcomes and mortality of 94 patients with acromegaly. Acta Neurochir 147:243-251

17. Kauppinen-Makelin R, Sane T, Reunanen A, Valimaki MJ, Niskanen L, Markkanen H, Loyttyniemi E, Ebeling T, Jaatinen P, Laine H, Nuutila P, Salmela P, Salmi J, Stenman UH, Viikari J, Voutilainen E (2005) A nationwide survey of mortality in acromegaly. J Clin Endocrinol Metab 90:4081-4086

18. Abosch A, Tyrrell JB, Lamborn KR, Hannegan LT, Applebury CB, Wilson CB (1998) Transsphenoidal microsurgery for growth hormone-secreting pituitary adenomas: initial outcome and longterm results. J Clin Endocrinol Metab 83:3411-3418

19. Biermasz NR, Dekker FW, Pereira AM, Van Thiel SW, Schutte PJ, Van DH, Romjin JA, Roelfsema F (2004) Determinants of survival in treated acromegaly in a single center: predictive value of serial insulin-like growth factor I measurements. J Clin Endocrinol Metab 89:2789-2796

20. Holdaway IM (2007) Excess mortality in acromegaly. Horm Res 68(Suppl 5):166-172

21. Swearingen B, Barker FG, Katznelson L, Biller BM, Grinspoon S, Klibanski A, Moayeri N, Black PM, Zervas NT (1998) Long-term mortality after transsphenoidal surgery and adjunctive therapy for acromegaly. J Clin Endocrinol Metab 83:3419-3426

22. Shimatsu A, Yokogoshi Y, Saito S, Shimizu N, Irie M (1998) Long-term survival and cardiovascular complications in patients with acromegaly and pituitary gigantism. J Endocrinol Invest 21(Suppl 8):55-57

23. Holdaway IM, Bolland MJ, Gamble GD (2008) A meta-analysis of the effect of lowering serum levels of GH and IGF-I on mortality in acromegaly. Eur J Endocrinol 159:89-95

24. Dekkers OM, Biermasz NR, Pereira AM, Romijn JA, Vandenbroucke JP (2008) Mortality in acromegaly: a metaanalysis. J Clin Endocrinol Metab 93:61-67

25. Sherlock M, Reulen RC, Alonso AA, Ayuk J, Clayton RN, Sheppard MC, Hawkins MM, Bates AS, Stewart PM (2009) ACTH deficiency, higher doses of hydrocortisone replacement, and radiotherapy are independent predictors of mortality in patients with acromegaly. J Clin Endocrinol Metab 94:4216-4223

26. Colao A, Ferone D, Marzullo P, Lombardi G (2004) Systemic complications of acromegaly: epidemiology, pathogenesis, and management. Endocr Rev 25:102-152 
27. Vilar L, Naves LA, Costa SS, Abdalla LF, Coelho CE, Casulari LA (2007) Increase of classic and nonclassic cardiovascular risk factors in patients with acromegaly. Endocr Pract 13:363-372

28. Davi' MV, Dalle Carbonare L, Giustina A, Ferrari M, Frigo A, Lo Cascio V, Francia G (2008) Sleep apnoea syndrome is highly prevalent in acromegaly and only partially reversible after biochemical control of the disease. Eur J Endocrinol 159:533-540

29. Van Thiel SW, Bax JJ, Biermasz NR, Holman ER, Poldermans D, Roelfsema F, Lamb HJ, van der Wall EE, Smit JW, Romijn JA, Pereira AM (2005) Persistent diastolic dysfunction despite successful long-term octreotide treatment in acromegaly. Eur $\mathbf{J}$ Endocrinol 153:231-238

30. Colao A, Marzullo P, Ferone D, Spinelli L, Cuocolo A, Bonaduce D, Salvatore M, Boerlin V, Lancranjan I, Lombardi G (2000) Cardiovascular effects of depot long-acting somatostatin analog sandostatin LAR in acromegaly. J Clin Endocrinol Metab 85:3132-3140

31. Colao A, Cannavo S, Marzullo P, Pivonello R, Squadrito S, Vallone G, Almoto B, Bichisao E, Trimarchi F, Lombardi G (2003) Twelve months of treatment with octreotide-LAR reduces joint thickness in acromegaly. Eur J Endocrinol 148:31-38

32. Bonadonna S, Mazziotti G, Nuzzo M, Bianchi A, Fusco A, De Marinis L, Giustina A (2005) Increased prevalence of radiological spinal deformities in active acromegaly: a cross-sectional study in postmenopausal women. J Bone Miner Res 20:18371844

33. Tolis G, Angelopoulos NG, Katounda E, Rombopoulos G, Kaltzidou V, Kaltsas D, Protonotariou A, Lytras A (2006) Medical treatment of acromegaly: comorbidities and their reversibility by somatostatin analogs. Neuroendocrinology 83:249-257

34. Ben-Shlomo A, Melmed S (2008) Somatostatin agonists for treatment of acromegaly. Mol Cell Endocrinol 286:192-198

35. Lombardi G, Galdiero M, Auriemma RS, Pivonello R, Colao A (2006) Acromegaly and the cardiovascular system. Neuroendocrinology 83:211-217

36. Matta MP, Caron P (2003) Acromegalic cardiomyopathy: a review of the literature. Pituitary 6:203-207

37. Colao A, Marzullo P, Cuocolo A, Spinelli L, Pivonello R, Bonaduce D, Salvatore M, Lombardi G (2003) Reversal of acromegalic cardiomyopathy in young but not in middle-aged patients after 12 months of treatment with the depot long-acting somatostatin analogue octreotide. Clin Endocrinol 58:169-176

38. Colao A, Spinelli L, Cuocolo A, Spiezia S, Pivonello R, di Somma C, Bonaduce D, Salvatore M, Lombardi G (2002) Cardiovascular consequences of early-onset growth hormone excess. J Clin Endocrinol Metab 87:3097-3104

39. Hradec J, Kral J, Janota T, Krsek M, Hana V, Marek J, Malik M (1999) Regression of acromegalic left ventricular hypertrophy after lanreotide: a slow-release somatostatin analog. Am J Cardiol 83:1506-1509

40. Baldelli R, Ferretti E, Jaffrain-Rea ML, Iacobellis G, Minniti G, Caracciolo B, Moroni C, Cassone R, Gulino A, Tamburrano G (1999) Cardiac effects of slow-release lanreotide: a slow-release somatostatin analog, in acromegalic patients. J Clin Endocrinol Metab 84:527-532

41. Lombardi G, Colao A, Marzullo P, Biondi B, Palmieri E, Fazio S (2002) Improvement of left ventricular hypertrophy and arrhythmias after lanreotide-induced GH and IGF-I decrease in acromegaly. A prospective multi-center study. J Endocrinol Invest 25:971-976

42. Colao A, Cuocolo A, Marzullo P, Nicolai E, Ferone D, Della Morte AM, Pivonello R, Salvatore M, Lombardi G (2001) Is the acromegalic cardiomyopathy reversible? Effect of 5-year normalization of growth hormone and insulin-like growth factor I levels on cardiac performance. J Clin Endocrinol Metab 86:1551-1557
43. Colao A, Cuocolo A, Marzullo P, Nicolai E, Ferone D, Florimonte L, Salvatore M, Lombardi G (1999) Effects of 1-year treatment with octreotide on cardiac performance in patients with acromegaly. J Clin Endocrinol Metab 84:17-23

44. Berg C, Petersenn S, Lahner H, Herrmann BL, Buchfelder M, Droste M, Stalla GK, Strasburger CJ, Roggenbuck U, Lehmann N, Moebus S, Jockel KH, Mohlenkamp S, Erbel R, Saller B, Mann K (2010) Cardiovascular risk factors in patients with uncontrolled and long-term acromegaly: comparison with matched data from the general population and the effect of disease control. J Clin Endocrinol Metab 95:3648-3656

45. Colao A, Lombardi G (1998) Growth-hormone and prolactin excess. Lancet 352:1455-1461

46. Barkan A (1997) Acromegalic arthropathy and sleep apnea. J Endocrinol 155(Suppl 1):S41-S44

47. Colao A, Marzullo P, Vallone G, Marino V, Annecchino M, Ferone D, De Brasi D, Scarpa R, Oriente P, Lombardi G (1998) Reversibility of joint thickening in acromegalic patients: an ultrasonography study. J Clin Endocrinol Metab 83:2121-2125

48. Colao A, Marzullo P, Vallone G, Giaccio A, Ferone D, Rossi E, Scarpa R, Smaltino F, Lombardi G (1999) Ultrasonographic evidence of joint thickening reversibility in acromegalic patients treated with lanreotide for 12 months. Clin Endocrinol 51: 611-618

49. Fatti LM, Scacchi M, Pincelli AI, Lavezzi E, Cavagnini F (2001) Prevalence and pathogenesis of sleep apnea and lung disease in acromegaly. Pituitary 4:259-262

50. Arosio M, Sartore G, Rossi CM, Casati G, Faglia G, Manzato E, Italian Multicenter Octreotide Study Group (2000) LDL physical properties, lipoprotein and $\mathrm{Lp}$ (a) levels in acromegalic patients. Effects of octreotide therapy. Atherosclerosis 151:551-557

51. Delaroudis SP, Efstathiadou ZA, Koukoulis GN, Kita MD, Farmakiotis D, Dara OG, Goulis DG, Makedou A, Makris P, Slavakis A, Avramides AI (2008) Amelioration of cardiovascular risk factors with partial biochemical control of acromegaly. Clin Endocrinol 69:279-284

52. Colao A, Marzullo P, Lombardi G (2002) Effect of a six-month treatment with lanreotide on cardiovascular risk factors and arterial intima-media thickness in patients with acromegaly. Eur J Endocrinol 146:303-309

53. Hua SC, Yan YH, Chang TC (2006) Associations of remission status and lanreotide treatment with quality of life in patients with treated acromegaly. Eur J Endocrinol 155:831-837

54. Trepp R, Everts R, Stettler C, Fischli S, Allemann S, Webb SM, Christ ER (2005) Assessment of quality of life in patients with uncontrolled versus controlled acromegaly using the acromegaly quality of life questionnaire. Clin Endocrinol 63:103-110

55. T'Sjoen G, Bex M, Maiter D, Velkeniers B, Abs R (2007) Healthrelated quality of life in acromegalic subjects: data from AcroBel, the Belgian registry on acromegaly. Eur J Endocrinol 157:411417

56. Matta MP, Couture E, Cazals L, Vezzosi D, Bennet A, Caron P (2008) Impaired quality of life of patients with acromegaly: control of GH/IGF-I excess improves psychological subscale appearance. Eur J Endocrinol 158:305-310

57. Badia X, Webb SM, Prieto L, Lara N (2004) Acromegaly quality of life questionnaire. Health Qual Life Outcomes 2:13

58. Didoni G, Grottol S, Gasco V, Battistini M, Ferone D, Giusti M, Ragazzoni F, Ruffo P, Ghigo E, Minuto F (2004) Cost-of-illness study in acromegalic patients in Italy. J Endocrinol Invest 27:1034-1039

59. Luque-Ramírez M, Paramo C, da Varela CC, Garcia-Mayor RV (2007) Cost of management of invasive growth hormone-secreting macroadenoma. J Endocrinol Invest 30:541-545

60. Murray CJ, Lopez AD (eds) (1996) The global burden of disease: a comprehensive assessment of mortality and disability from 
diseases, injuries, and risk factors in 1990 and projected to 2020. Harvard University Press, Cambridge

61. Tosteson AN, Burge RT, Marshall DA, Lindsay R (2008) Therapies for treatment of osteoporosis in US women: cost-effectiveness and budget impact considerations. Am J Manag Care $14: 605-615$

62. Lloyd-Jones D, Adams R, Carnethon M, De Simone G, Ferguson TB, Flegal K, Ford E, Furie K, Go A, Greenlund K, Haase N, Hailpern S, Ho M, Howard V, Kissela B, Kittner S, Lackland D, Lisabeth L, Marelli A, McDermott M, Meigs J, Mozaffarian D, Nichol G, O’Donnell C, Roger V, Rosamond W, Sacco R, Sorlie P, Stafford R, Steinberger J, Thom T, Wasserthiel-Smoller S,
Wong N, Wylie-Rosett J, Hong Y (2009) Heart disease and stroke statistics-2009 update: a report from the American heart association statistics committee and stroke statistics subcommittee. Circulation 119:480-486

63. Kapur V, Blough DK, Sandblom RE, Hert R, de Maine JB, Sullivan SD, Psaty BM (1999) The medical cost of undiagnosed sleep apnea. Sleep 22:749-755

64. Ray GT, Collin F, Lieu T, Fireman B, Colby CJ, Quesenberry CP, Van den Eeden SK, Selby JV (2000) The cost of health conditions in a health maintenance organization. Med Care Res Rev 57:92-109 